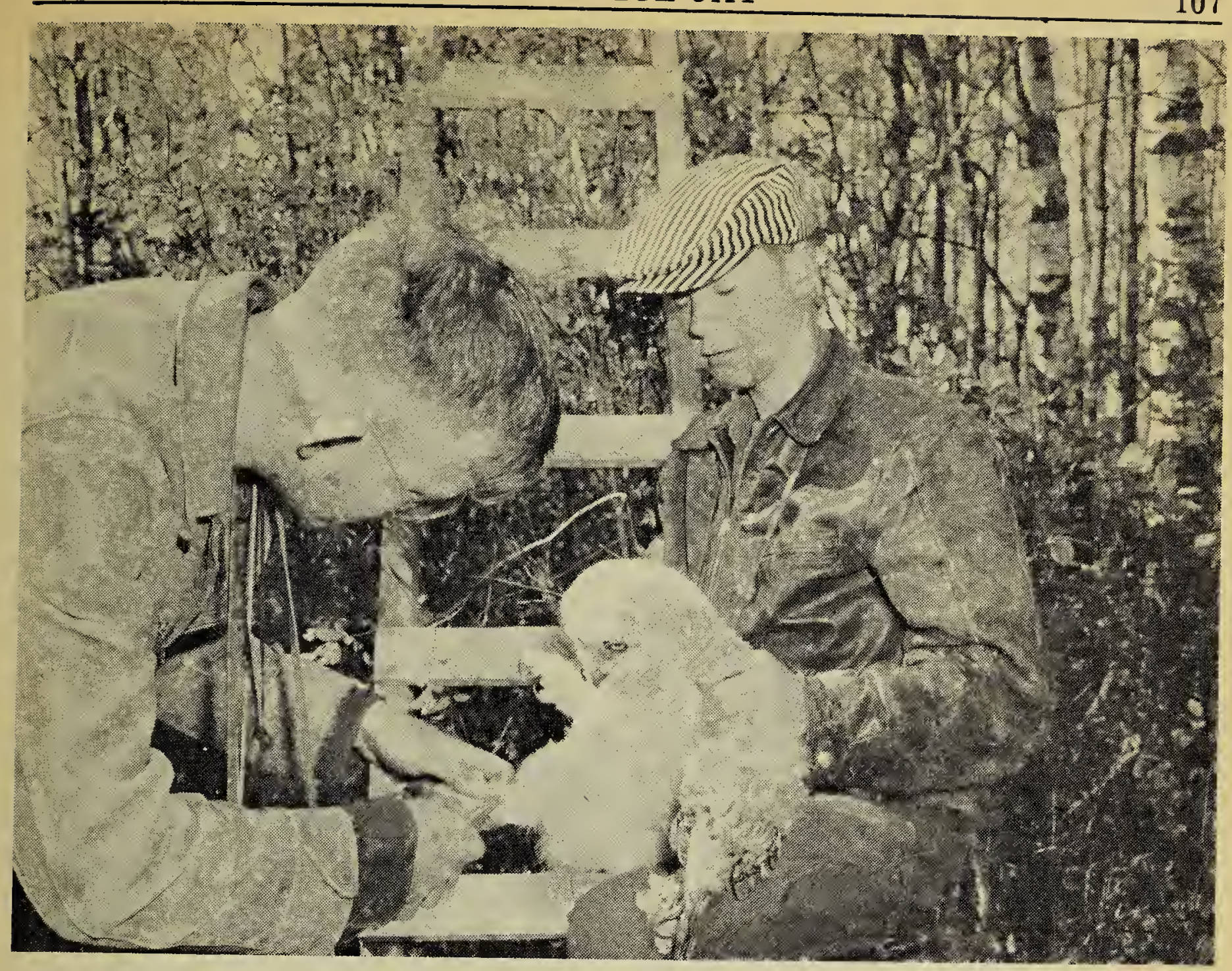

Photo by Cliff Shaw

Dr. Houston (left) and Bill Horseman (right) band a young Great Horned Owl.

each, four nests had two, and four had one. Thus we banded 40 Great Horned Owls in a single day. I was fortunate in having three excellent climbers: Bill Horseman and his friend Lorne Barker of 'S ltcoats, and Gary Anweiler of Melville.

Horseman continued to scout for nests, and in addition one was found by Anweiler at Melville and four at Stornoway by Ken Swartz and Stanley Zazelenchuk. These necessitated a few early morning and late evening trips until finally the last two late nests were visited on June 6. The final total was 70 Great Horned Owls banded; 67 for 30 nests, plus three other young already out of the nest and flying short distances.

We saw a good sampling of the nestling's food in each nest. Rabbits and pocket gophers were the predominant items, but grebes, ducks, crows and rats were frequently found. Not a single upland game bird was represented, though a Ruffed Grouse was drumming on his wellworn $\log$ less than twenty feet from the base of the tree containing one of the owl's nests. Neither was a single domestic fowl encountered in any of the thirty nests examined.

We have also banded 12 Longeared Owls in four nests and 16 Red-tailed Hawks in nine nests to date this year.

\title{
A Study of Early Spring Nesting of the Horned Lark in the Area of Kindersley, Sask.
}

\section{by Glen A. Fox, Kindersley, Sask.}

During April of 1959, I made a study of eight nests of the Horned Lark (Eremophila alpestris). The study was carried out over a period of 35 days and a total of 70 hours. Observations of incubation and brooding were aided by a $20 \mathrm{x}$ spotting scope. None of the birds studied was marked.

\section{ENVIRONMENT}

The study area was a typical grassland area of the prairies. The nests were located on a golf course. Vegetation in this area included prairie grasses, sage, cactus, dock and cattails. Mammals noted in this area were the meadow vole, deer mouse, masked shrew, Richardson's ground 
squirrel and white-tailed jackrabbit.

\section{TERRITORY}

Both sexes arrived about March 15 and established territory within three or four days. The male proclaimed his territory by singing from an appropriate perch. Territorial defense against other horned larks consisted of chasing the intruder for a period of usually a minute or less. Bodily contact during the pursuit was rare, being observed only once when the intruder was driven to the ground. The female protested territorial violation with a "te-te" call. Territorial defense was stronger during brooding and the latter part of the incubation period than it was during the early part of incubation. The male tolerated other species in his territory. The male was observed chasing a chestnut-collared longspur and a ring-billed gull in the same manner that a kingbird attacks a crow. Average size of the territory was 8,000 square feet.

\section{MATING}

Mating began as soon as territory was established and courtship flight was observed, as described by A. A. Allen as early as March 18: "Starting from the ground ... the male bird mounts upward on a grand spiral until it is almost out of sight. Then, as a tiny speck in the blue, it hovers and sings. . . . closing its wings, the Lark plunges headlong towards the earth. Like a plummet it drops, until one feels sure he will see it dashed to death against the ground. For hundreds of feet it plunges unchecked; then, within a few feet of the ground, it spreads its wings, shoots abruptly forward, checking its momentum, and gracefully alights as though nothing had happened." (Allen, 1930).

\section{NESTING}

The nest site is picked and nest built by female only. The weight of one nest was 17 gms., average top diameter was $95 \mathrm{~mm}$., interior diameter was $64 \mathrm{~mm}$. and average depth was $55 \mathrm{~mm}$. One nest was composed of 1,550 pieces of dead grasses, rootlets, paper and paper fibres.

Dummy nests were depressions in the ground which were possibly used as roosts for the off-duty bird. The depressions were unlined. Pettingill (1956) suggests that most ground nesting birds scratch numerous depressions in the ground and attempt to mould them to suit their body contours before picking the final nest site. Each dummy nest contained excreta.

The eggs are greenish-grey, thickly spotted with dark olive and pale laverder, with an occasicnal dark brown scrawl. Ten eggs averaged $15.40 \mathrm{x}$. $20.40 \mathrm{~mm}$. in diameter and length. Average weight of the fresh egg was 2.8 gms. The fresh egg lost .15 gms. daily until it reached a low of 1.6 gms. the day before hatching.

The eggs were laid at daily intervals, usually in the early morning. The average number of eggs in the clutch was three.

Nesting starts in April and during 1959 the earliest laying was April 8, the earliest hatching April 19, earliest nest leaving May 2.

No parasitism occurred.

The female incubates the eggs both night and day as soon as the last egg is laid. The incubation period was 10 days. The eggs were turned at hourly intervals. The incubating bird showed a period of uneasiness for about five minutes before leaving the nest to feed.

\section{DEVELOPMENT OF YOUNG}

The newly-hatched young was covered with a yellow-orange down on the capital, spinal, humeral and femoral tracts. Bill was grey-yellow in color with white egg-tooth. The eyes were closed. Feather tracts appeared at two days of age. Primaries protruded $3 \mathrm{~mm}$. at four days of age and $10 \mathrm{~mm}$. at six days and $24 \mathrm{~mm}$. at eight days of age. Rectrices began to show at four days of age and were 18 $\mathrm{mm}$. long on the ninth day. Young were completely covered with feathers at 10 days of age.

Based on one to five, the average weight of nestlings at hatching was 1.8 grams and they gained about 1.5 gms. daily for the first four days. The greatest gain of all took place between the fourth and fifth days where the nestling's weight increased 8.3 gms. The nestlings gained about $2 \mathrm{gms}$. daily from the fifth to eighth day of nestling life.

The wing measured $6 \mathrm{~mm}$. when the young had hatched and increased about $2 \mathrm{~mm}$. daily until the sixth day when an increase of $8.5 \mathrm{~mm}$. occurred. An increase of $9.5 \mathrm{~mm}$. occurred between six and seven days of age. The tarsus measured $12 \mathrm{~mm}$. at hatching and gained $2 \mathrm{~mm}$. daily 


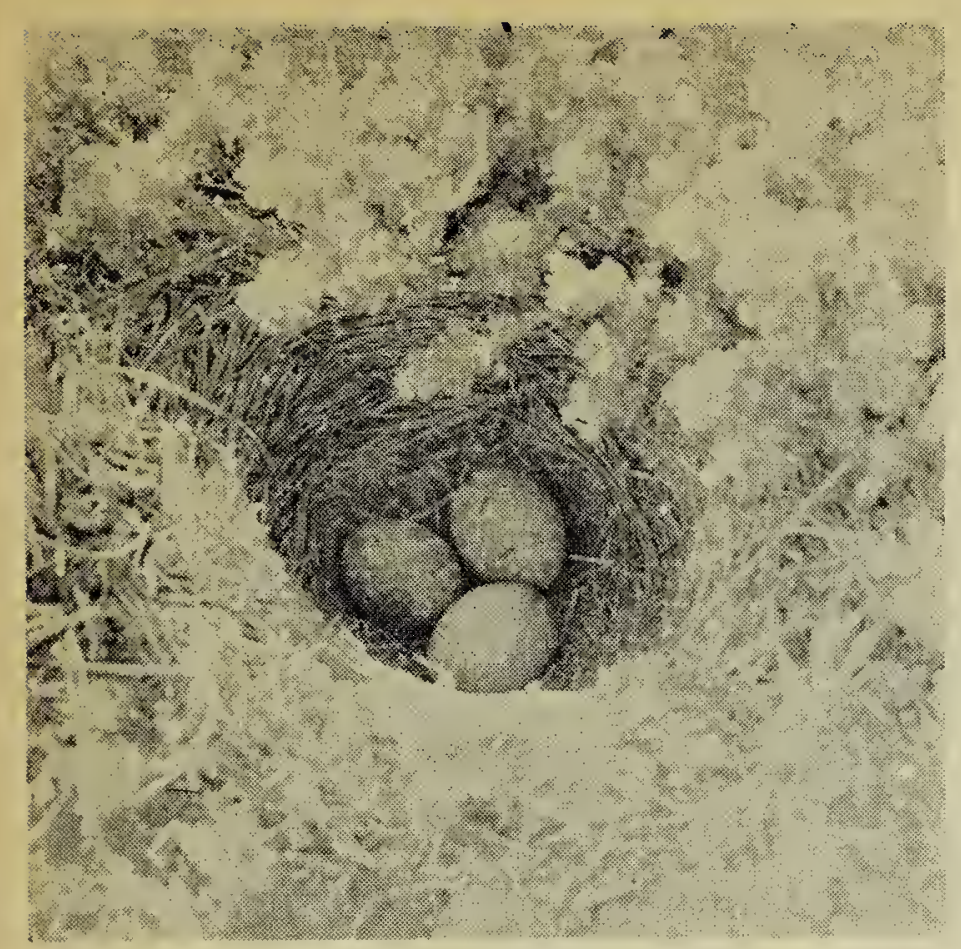

Fig. 1. Nest of the Horned Lark.

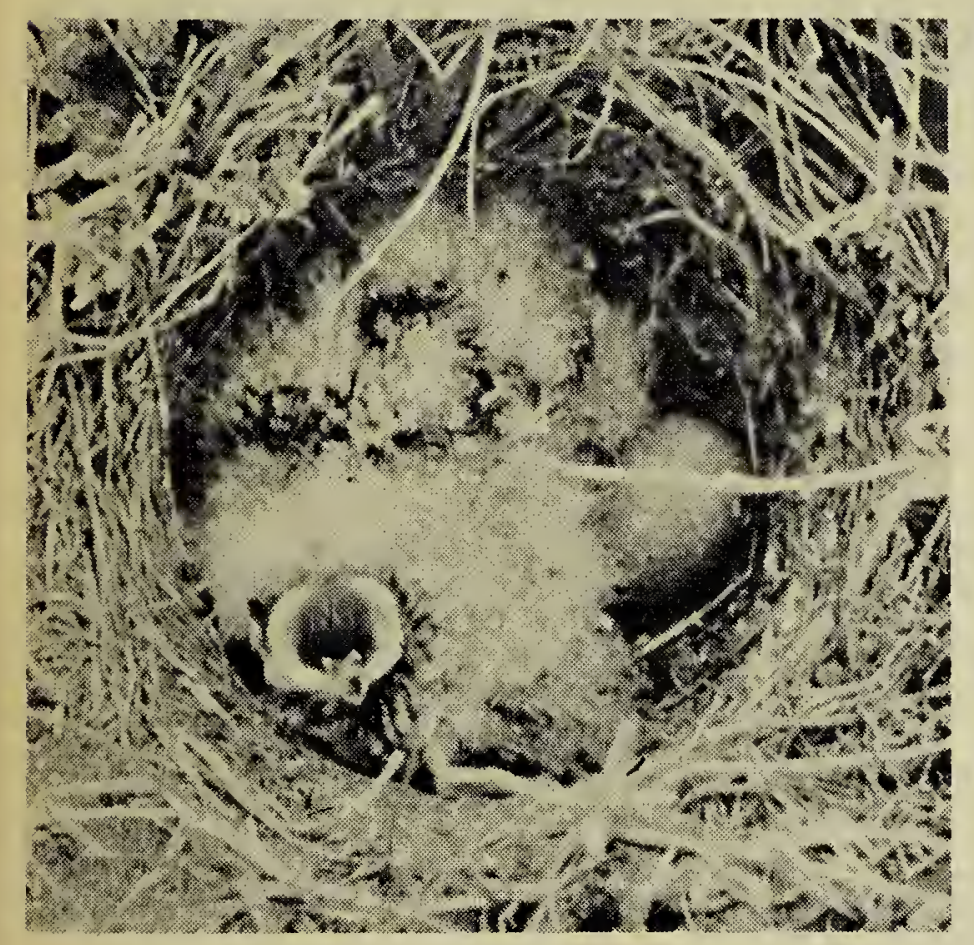

Fig. 3 Young at 7 days.

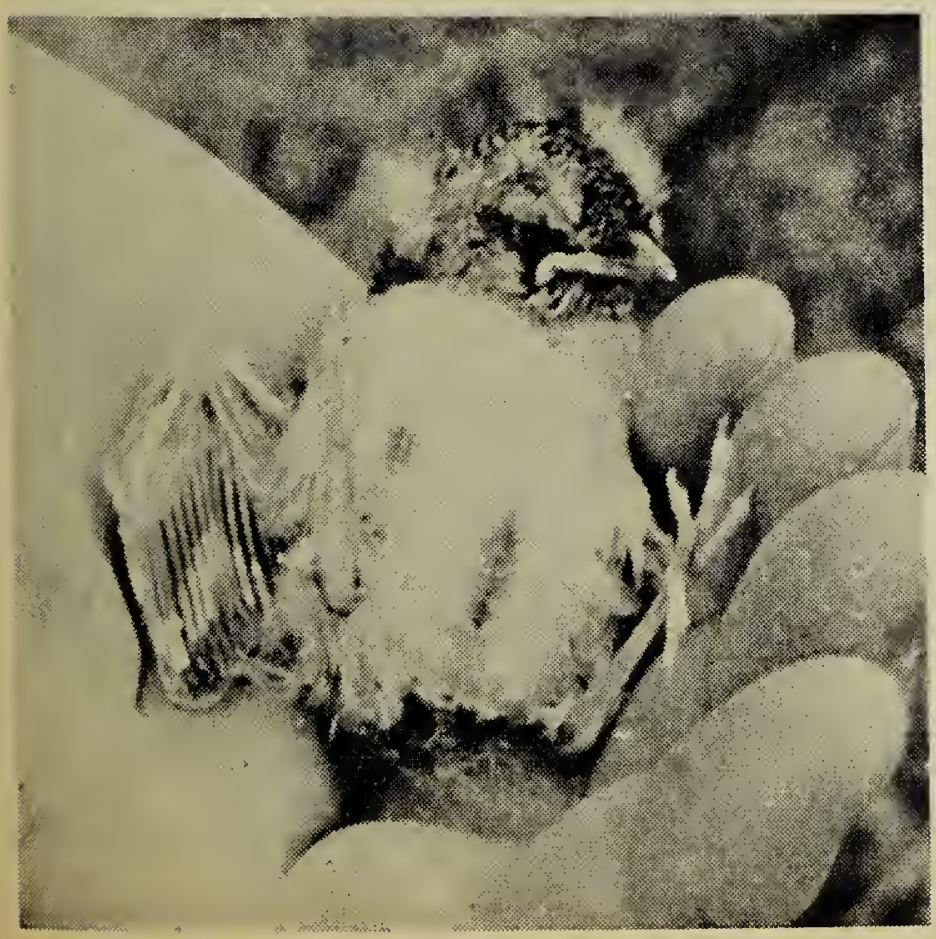

Fig. 4. Young at 9 days. until the fifth day when it measured $22 \mathrm{~mm}$. which was the final size. Culmen was $4.5 \mathrm{~mm}$. at hatching and gained $1 \mathrm{~mm}$. daily until the second day when it increased $1 \mathrm{~mm}$. every three days.

The average bird measured as follows at nest leaving: wing, 45 $\mathrm{mm}$., tarsus, $22 \mathrm{~mm}$., culmen, $8 \mathrm{~mm}$.

The diet of the young was mainly insects. A food call could be heard at three days of age, a low "zee-zeezee."

The nestlings began to show fear when seven days old. The young answered their parents with a "tee-e" location call at ten days of age. They left the nest when 9 to 11 days old.

\section{PARENTAL CARE}

Brooding began as soon as young had hatched and continued until young were seven days old. The female did all of the brooding.

Feeding commenced when the young were one or two hours old. Feeding was carried out by both sexes and the number of feeding visits decreased as the young got older. The brooding female would get off the nest and allow the male to feed young; when the male left she would again settle on the nest and brood.

Nest sanitation was carried out by both sexes, the larger fecal sacs were carried away, the smaller ones eaten.

\section{NESTING SUCCESS}

Nesting success was very poor$25 \%$. This was due to a freak twoday blizzard at the peak of incubation. Two clutches of eggs were lost due to freezing as well as one set of nestlings. Three clutches were lost to an unknown predator.

\section{LITERATURE CITED}

ALLEN, A. A. 1930 Book of Bird Life. D. Van Nos1930 Book of Bird Life. $D$.
trand Company, New York, 60-61.

PETTINGILL, OLIN SEWALL, JR. 1956 A Laboratory and Field Manual of 1956 A Laboratory and Fishing Company, Minneapolis.

\section{ACKNOWLEDGMENTS}

I would like to express my appreciation to Mr. J. B. Gollop and Mr. Alex Dzubin for their encouragement and help in criticizing the original manuscript. 